\title{
Climate change and health in the Mid-Atlantic Region
}

\author{
Keith Benson ${ }^{1}$, Patricia Kocagil ${ }^{2}$, J ames Shortle ${ }^{2, *}$ \\ ${ }^{1}$ M anagement and M arketing Department, Winthrop University, Rock Hill, South Carolina 29733, USA \\ ${ }^{2}$ Department of Agricultural Economics and Rural Sociology, The Pennsylvania State University, University Park, \\ Pennsylvania 16802, USA
}

\begin{abstract}
This paper assesses potential health impacts from climate change in the Mid-Atlantic Region (MAR). It draws on diverse sources of information including health statistics and current climate and health literature. Climate projections for 2030 and 2095 from the Hadley Centre for Climate Prediction and Research and the Canadian Centre for Climate M odeling and Analysis are used. They indicate a warmer, wetter and possible stormier climate for the M AR. M orbidity and mortality from extreme events may increase somewhat. Although more speculative, climate change could increase the region's risk from water-borne and vector-borne diseases. The region's current and future health infrastructure are expected to be able to respond to the health risks, although at increased cost from measures to protect the safety of food and water, control disease vectors, and provide health services. The elderly and those with limited access to health care could be disproportionately affected.
\end{abstract}

KEY WORDS: Climate change $\cdot$ Health impacts

\section{INTRODUCTION}

Recent reports by the Intergovernmental Panel on Climate Change (IPCC) (M cMichael et al. 1996) and the World Health Organization (WHO) (WHO 1990, 1996) catalogue many ways that climate change could affect human health. Examples include changes in the frequency and intensity of extreme events such as heat waves, floods, and wind storms, changes in the geographic range and activity of disease vectors such as mice and mosquitoes, changes in weather conditions affecting air and water quality, and changes in food supplies due to changes in growing conditions. Focusing at the global scale, the IPCC (MCMichael et al. 1996) and WHO (1996) conclude that, on balance, adverse health impacts of projected climate change will substantially outweigh the beneficial health impacts.

\footnotetext{
*Corresponding author.
}

E-mail: jss15@psu.edu
Because climatic and non-climatic factors affecting health vary across geographical areas and change over time, the relative importance of climate to human health varies from region to region and within regions over time (Patz et al. 1996, M cM ichael 1997). This article explores potential health impacts from climate change in the Mid-Atlantic Region (MAR). Interest in the impacts of climate change on human health was strongly voiced at the initial Workshop on Climate Change Impacts in the MAR (Fisher et al. 1999). Participants' concerns included increased illness and mortality related to more frequent and/or severe extreme heat events, new or re-emergent diseases because of changes in the dynamics of transmission, distribution and resistance of disease agents, and increased contamination of public and private water supplies due to increased flooding.

To provide context, we begin with an overview of the region's current health status and stresses, and relationships between climate and health. Next, we examine selected climate-related health risks in the region. 


\section{CURRENT HEALTH STATUS AND STRESSES}

Health is a complex function of many factors including lifestyle choices (e.g. cigarette and alcohol consumption, diet, fitness), access to medical care (availability, quality and price of care as well as health insurance status), medical technology, genetic endowment (predisposition to certain diseases), and characteristics of the built and natural environment (Banta \& J onas 1996). The advanced health systems in the US have made it one of the healthiest countries in terms of key health indicators such as mortality rate, infant mortality rates, and life expectancy (WHO 1998). In 1997, the US crude ${ }^{1}$ mortality rate was 865 per 100000 population, the infant mortality rate was 7 per 1000 live births and life expectancy at birth was $77 \mathrm{yr}$ (WHO 1998, CDC 1999a). The MAR similarly enjoys high health standards (Kocagil et al. 1999).

The 3 leading causes of death in the MAR, as in the US, are heart disease, cancer and stroke (Kocagil et al. 1999). Age-adjusted mortality rates ${ }^{2}$ in the MAR (US) in 1995 for these 3 causes of death were 286 (281), 210 (205), and 54 (60) per 100000 population, respectively. Although climate can be an aggravating or contributing factor (see discussion below), genetic endowment and behavioral choices are major determinants of these causes of death (CDC 1998). Currently, there is very little mortality directly (i.e. reported on death certificates) attributable to cold, heat, storms, flooding or lightning in the MAR. The average annual ageadjusted mortality rate in the M AR from 1990 to 1996 for a combined weather-related category that includes deaths from heat, cold, storm, flood, and lightning was only 0.13 deaths per 100000 population (Kocagil et al. 1999). This is much lower than rates from the 3 leading causes of death in the region as discussed above. However, when summer and winter temperature extremes are related to all causes of death, the region exhibits more temperature-related mortality, particularly heatrelated, than other regions of the US (Kalkstein \& Greene 1997). Examples include deaths from heart disease during heat waves. While this is a matter of concern, such temperature-related mortality rates are very low (Chestnut et al. 1995).

While the MAR enjoys good health by international standards, there are some segments of the MAR population that are vulnerable to health threats primarily due to age, poverty, and lack of access to medical services. Examples for 1995 include: 15.7\% of the Plateau

\footnotetext{
${ }^{1}$ The ratio of the number of deaths in a given population to the population, unadjusted for age composition of the population

${ }^{2} \mathrm{Age}$-adjusted mortality rates take into account the age distribution of a population. The US population in 1995 is used as the standard population
}

region of the MAR was aged 65 and older as compared to the national average of $12.8 \%$, the average per capita income of the Ridge and Valley region of the M AR was $\$ 18277$ compared to the national average of $\$ 21651$; and $17.3 \%$ of the population in Washington, DC, is uninsured compared to the national rate of $15.4 \%$.

\section{HEALTH SENSITIVITY AND VULNERABILITY TO CLIMATE CHANGE}

General circulation model (GCM) results produced for the United States Global Climate Research Program (USGCRP) National Assessment for the years 2030 and 2095 indicate that the MAR will become somewhat warmer, although it has one of the lowest levels of projected future warming among US regions (see Polsky et al. 2000, in this issue). The largest increases are in winter minimum temperatures. The GCM results also indicate significant increases in precipitation and in variance of precipitation. The Hadley model projects the greatest increase in summer while the CCC (Canadian Centre for Climate M odeling and Analysis) GCM projects little summer increase but a large winter increase. Because of the uncertainty of these models, we focus on the potential health effects of a somewhat warmer and possibly much wetter $M A R$.

The effects of climate change on human health can be through direct or indirect pathways (M CM ichael et al. 1996, WHO 1996). Direct effects would occur predominantly through changes in the frequency and severity of weather events (e.g. temperature, wind, precipitation) that directly effect human physiology or psychology. Indirect effects of climate change on health would occur predominantly through the effect of climate on other biological or geophysical systems that influence human health. For example, climate change could influence the range and activity of disease vectors, the ecology of water-borne and foodborne infectious agents, the levels and biological impacts of air pollutants, and the productivity of food systems.

Direct health effects from a climate change are the best understood and have received the most attention in the literature on climate impacts on human health. Because indirect health effects involve a complex chain of causality from climate change through biophysical systems to human disease risks, they are more difficult to quantify (Haines \& McMichael 1997). Yet, the emerging view of health impacts at the global level suggests that indirect impacts may be substantially more important than direct impacts (McMichael et al. 1996). 
Human health sensitivity to climate does not necessarily imply significant risk or vulnerability to global climate change. Even if climate change causes certain health risks in the region to increase, the region could adapt to reduce its vulnerability. The impacts of weather and ecological change on human health in a region are moderated by a number of factors. In the short to medium term, these factors include the protection or risks associated with the region's existing natural and built environment, genetic endowment, socioeconomic conditions, population density, age, health, immune and nutritional status, access to health care, and public water and sanitation (Kalkstein et al. 1996). Presently: (1) Most people in the MAR live and work in structures that protect them from the elements; many of their structures have sophisticated climate control systems. These structures are adaptations to the existing climate. (2) M ost people in the MAR have access to water and sanitation systems that provide potable water and treat wastes. The region also has significant regulation to protect the safety of drinking water and foods. These systems reduce risks from water-borne and other diseases. (3) Most people in the MAR have access to modern medical services that can provide them with vaccines and treatments against most communicable diseases that might migrate to the region. (4) The region has modern food and energy distribution systems that reduce the importance of local production, and therefore local climate, for food and energy supplies.

In the medium to long term, climate change, and, indeed, expectations of climate change, are likely to induce private and public responses to reduce vulnerability to health and other climate related risks (Patz 1996, Abler et al. 2000). Human history has been shaped by adaptations to new environments, ranging from the cold, barren Arctic tundra to the hot, arid deserts. For instance, in the US, the strength of the relationship between mortality and extreme temperatures has declined through the 20th century due to factors such as technological changes in housing construction and medical care (Larsen 1990). Factors that influence adaptation include options that are (or will become) available and their effectiveness, costs and secondary impacts. Examples include concerns about unintended impacts on non-target species from spraying to control mosquitoes and concerns that control measures might not be used by some vulnerable groups such as people who cannot afford them. The slightly warmer and wetter MAR projected for 2030 and 2095 remains a temperate climate well within the range experienced by developed nations.

Nevertheless, the projected climate change could have some health consequences as well as impacts on the costs of public health. We selected several broad areas of potential concern for our assessment. These are the impacts of climate change on nutritional status, extreme events, heat- and cold-related mortality, vector/water/food-borne diseases, and air quality. Our choices were guided by the input of MARA (MidAtlantic Regional Assessment) stakeholder groups, the results of climate modeling indicating the projected climate change for the region, and the results of prior research.

\subsection{N utritional status}

M alnutrition causes infant mortality, stunts the physical and mental development of children, increases susceptibility to infectious disease by impairing the immune system, and contributes to other adverse health effects. Although a major problem in some regions of the world, malnutrition due to limited access to healthy foods is not a problem in the MAR. In 1995, the nutritional deficiency mortality rate in the MAR (1.0 per 100000 people) was lower than the national rate (1.4) (Kocagil et al. 1999). Some segments of the population are at risk though. For instance, in 1995, $26 \%$ of West Virginia's population received food stamps compared to the national rate of $10 \%$ (US Census Bureau 1998). However, agriculture's obvious sensitivity to climate has led to concerns about the impacts of climate change on human health resulting from changes in the cost and availability of food (Houghton et al. 1990, Kendall \& Pimentel 1994). The consensus of several assessments of potential impacts on US and world agriculture is that global climate change probably will not threaten global food supplies (Abler \& Shortle 2000, in this issue). Food systems in the MAR are well integrated into national and global markets, with much of the food now consumed in the MAR being imported from other regions. Barring a global food supply catastrophe, adverse climate impacts on the nutritional status of the MAR appear highly unlikely.

\subsection{Extreme events}

One of the anticipated effects of climate change is an increase in intensity and frequency of extreme events such as hurricanes and floods. Extreme events can directly cause injuries and death and can have indirect consequences as well (e.g. floods can contaminate drinking water supplies). However, forecasts of storm tracks under climate change in the M AR are necessary in order to make any predictions about the resulting impacts on health in the region. At this time, such forecasts are not available. Moreover, while the health 
consequences of hurricanes and floods are apparent, those of other types of weather are not. For example, fewer motor vehicle accident fatalities occur in snowy or rainy weather (Loeb 1985, Zlatoper 1987), perhaps because people drive less frequently and/or more carefully in such weather. Interestingly, while the MAR is currently a flood-prone area, few deaths are directly attributed to flooding. The average annual crude mortality rate from 1990 to 1996 for a combined storm/flood/lightning category was only 2 deaths per 10 million population in the MAR, which is less than the corresponding US mortality rate of 6 deaths per 10 million population (Kocagil et al. 1999). The fact that mortality risks from extreme events are currently very small means that modest changes in these risks would have little impact on the region's health status. Furthermore, if weather events that pose threats to health become more frequent or severe, there are structural and nonstructural measures that can be undertaken to reduce vulnerability. These measures include building codes, land-use planning, and severe weather warning systems.

\subsection{Heat- and cold-related mortality}

The intensity and frequency of thermal extremes may also be altered by climate change. If climate change causes higher temperatures in the MAR, as predicted by the Hadley Centre climate model (see Polsky et al. 2000), reductions in cold-related mortality and morbidity and increases in heat-related mortality and morbidity can be expected. Kalkstein \& Greene (1997) use a spatial synoptic classification (SSC) approach to examine the relationship between weather and mortality in 44 US cities under current and climate change conditions. Five of these cities are located in the M AR. Kalkstein \& Swift (1998) focus on the findings for these cities, i.e. Baltimore, Greensboro, Philadelphia, Pittsburgh, and Washington, DC. Kalkstein \& Greene (1997) and Kalkstein \& Swift (1998) identify air masses currently associated with high mortality during summer and winter. They find that dry tropical and moist tropical air masses are most often associated with summer mortality. Using 3 GCM s (the Geophysical Fluid Dynamics Laboratory [GFDL], the United Kingdom Meteorological Office [UKMO], and the Max Planck Institute for Meteorology models), Kalkstein \& Greene (1997) and Kalkstein \& Swift (1998) predict how the frequency of these high risk air masses might change in 2020 and 2050 with climate change. Their findings show increases in the frequency of summer high risk air masses and little change in frequency of winter high risk air masses under climate change.
Kalkstein \& Greene (1997) apply the current mortality-climate relationships assuming full acclimatization to the future scenarios to estimate excess mortality (i.e. mortality above typical levels) due to the high risk air masses. The mortality-climate relationships of analog cities (i.e. cities that currently have a climate similar to the projected climate of the MAR cities) are used to adjust excess mortality for acclimatization. Future demographic changes such as changes in the age distribution of the population may be especially important for heat-related mortality. Thus, Kalkstein \& Greene's mortality estimates are adjusted for projected population changes following the methodology of Chestnut et al. (1995). City-specific population growth rates for 2 age categories (65 and older and under 65) are applied to Kalkstein \& Greene's estimates to incorporate population changes over time (NPA 1999).

Table 1 shows for each city the population-adjusted net excess mortality (i.e. the change in excess mortality between the future and current scenarios) that is attributable to climate. The impacts of climate change are projected to increase summer excess mortality in Philadelphia, Baltimore, Pittsburgh, and Greensboro. Winter mortality is not as strongly associated with air masses as summer mortality, and small changes in winter excess mortality are projected (with winter excess mortality projected to be lower in Philadelphia but higher in Pittsburgh and Washington, DC). Combining the summer and winter projections reveals that annual excess deaths in 2050 could increase by 137 to $184 \%$ in Baltimore, 169 to $200 \%$ in Greensboro, 103 to $244 \%$ in Philadelphia, 128 to $210 \%$ in Pittsburgh, and 15 to $100 \%$ in Washington, DC.

It is important to note that the results vary widely depending on the GCM used and that these studies did not use the 2 GCM s serving as a basis for comparison in the National Assessment process. In addition, future population changes do effect the projections. The population adjusted net mortality figures of 2050 are 31 to $600 \%$ higher, depending on the city and GCM , than the unadjusted figures, reflecting primarily the increase in the proportion of the population aged 65 plus. Between 1980 and 2050, the total populations of Baltimore, Greensboro and Philadelphia are projected to increase while the populations of Pittsburgh and Washington, DC, are projected to decrease. However, the proportion of the population aged 65 and over is projected to increase for all 5 cities. The growth in the elderly population is a modest $15 \%$ for Washington, DC, but is quite high for the other cities: $91 \%$ for Pittsburgh, 105\% for Philadelphia, 198\% for Baltimore, and 312\% for Greensboro. The non-elderly (less than age 65) population is projected to decrease by about 19\% in Pittsburgh and Washington, DC, increase modestly by $5 \%$ in Philadelphia and increase by $42 \%$ in Baltimore and $56 \%$ in Greensboro. 
Table 1. Net excess mortality assuming acclimatization and adjusted for projected population changes. Adapted from Kalkstein \& Greene (1997) and Kalkstein \& Swift (1998)

\begin{tabular}{|c|c|c|c|c|c|c|}
\hline & GFDL & $\begin{array}{c}2020 \\
\text { UKMO }\end{array}$ & Max Planck & GFDL & $\begin{array}{c}2050 \\
\text { UKMO }\end{array}$ & Max Planck \\
\hline \multicolumn{7}{|l|}{ Summer } \\
\hline Baltimore & -8 & 106 & -3 & 127 & 171 & 134 \\
\hline Greensboro & 28 & 38 & 28 & 55 & 59 & 49 \\
\hline Philadelphia & -8 & 361 & 122 & 282 & 682 & 416 \\
\hline Pittsburgh & -1 & 47 & 44 & 66 & 107 & 129 \\
\hline Washington, DC & 0 & 0 & 0 & 0 & 0 & 0 \\
\hline \multicolumn{7}{|l|}{ Winter } \\
\hline Baltimore & 0 & 0 & 0 & 0 & 0 & 0 \\
\hline Greensboro & 0 & 0 & 0 & 0 & 0 & 0 \\
\hline Philadelphia & 24 & -79 & 13 & -29 & -82 & 63 \\
\hline Pittsburgh & 6 & 15 & 7 & 22 & 27 & 16 \\
\hline Washington, DC & 12 & 19 & 11 & 3 & 21 & 16 \\
\hline \multicolumn{7}{|c|}{ Total (summer + winter) } \\
\hline Baltimore & -8 & 106 & -3 & 127 & 171 & 134 \\
\hline Greensboro & 28 & 38 & 28 & 55 & 59 & 49 \\
\hline Philadelphia & 16 & 283 & 135 & 254 & 600 & 478 \\
\hline Pittsburgh & 4 & 62 & 51 & 88 & 134 & 145 \\
\hline Washington, DC & 12 & 19 & 11 & 3 & 21 & 16 \\
\hline
\end{tabular}

Kalkstein \& Swift (1998) find that the cities in the MAR would experience more increases in heat-related mortality with climate change than other cities in the US. They attribute this in part to the infrequent but intense heatwaves that the region experiences. The frequency and timing of extreme temperatures affect acclimatization to the weather. For instance, fluctuations in winter temperatures have a larger effect on mortality in southern states in the US where colder temperatures are experienced less frequently (Larsen 1990). Chestnut et al. (1998) find that acclimatization to hot weather may be impeded in areas where minimum temperature variability is greatest. Thus, the impact of climate change on minimum temperature variability may be an important factor for determining the magnitude of heat-related mortality under climate change. In addition to acclimatization, heat waves may effect cities to differing degrees because of varying building materials, architectural styles, and degrees of air conditioning usage (Kilbourne 1997). Adaptation to reduce the urban heat island effect can be achieved by future urban planning. However, Kalkstein \& Swift (1998) suggest that cities in the MAR already have widespread air conditioning usage so that increased usage cannot be expected to further reduce vulnerability to heat-related mortality.

In sum, climate-related mortality is currently a minor problem in the MAR. Climate change may cause potentially large percentage increases in excess mortality, but mortality rates due to heat and cold extremes would remain low (Chestnut et al. 1995, Kocagil et al. 1999). However, this analysis may be under-reporting the impact of climate change because it examines only mortality. Climate change will influence morbidity as well, although a lack of morbidity data makes this difficult to quantify at this time. Further studies are needed to examine the magnitude of the impact of climate change on temperature-related morbidity as well as the associated costs.

\subsection{Vector-, water-, and food-borne illnesses}

A more complex and speculative relationship is the impact of climate change on vector-, water- and foodborne diseases. Much of the research to date focuses on the migration of tropical diseases to more temperate zones (Patz et al. 1996, Colwell et al. 1998). Few tropical diseases are common in the MAR (Kocagil et al. 1999). However, there are vector-borne diseases in the MAR that could be influenced by climate change, such as Lyme disease, encephalitis and hanta virus. A brief discussion of potential health impacts climate change on malaria, cholera, and Lyme disease are offered below. This is followed by a more detailed analysis of cryptosporidiosis.

Malaria currently is not common in the MAR (Kocagil et al. 1999). However, a warmer and wetter climate could make conditions favorable for the mosquito vector and increase the risk of malaria. Based on experiences in other developed countries (e.g. Australia), vulnerability to malaria can be reduced by vector controls, disease monitoring and medical treatment. A key component of reducing vulnerability is 
educating physicians to recognize diseases not common to the region.

Vibrio cholerae, the bacterium that causes cholera, is present in the Chesapeake Bay (Colwell et al. 1998) although the disease is not currently a health problem in the MAR. Preliminary research indicates that climate change could facilitate the growth of $\mathrm{V}$. cholerae in the Chesapeake Bay (Gibson 1999). Thus the risk of cholera in the MAR could increase with climate change. However, areas where cholera is currently a major health problem are countries with less developed public health infrastructure than the US. Proper food preparation and waste and water treatment can effectively reduce vulnerability to the disease.

Lyme disease is the most prevalent vector-borne disease in the MAR. Lyme disease rates in the MAR are more than twice the nation's (Kocagil et al. 1999). One way this disease is linked to the climate is by the range and activity of its host vector, the deer tick, which requires certain temperature and humidity conditions (Glass 1995). Links have also been made between acorn production, gypsy moth outbreaks and Lyme disease risk (J ones et al. 1998). The impact of climate change on the risk of contracting Lyme disease is a concern for the MAR (Patz \& Yap 1998). Like malaria, adaptation measures can reduce vulnerability to the disease. Vector controls, prevention, vaccination and early detection are some examples. Research suggests that at this time, it is cost effective to vaccinate only those individuals who spend a lot of time outdoors in areas of high Lyme disease risk rather than everyone (CDC 1999b, Meltzer et al 1999). In addition, vaccinated people inadvertently may put themselves at higher risk, presuming the vaccine will be more effective than clinical trials have shown. Its cost (currently about \$250) may leave lower income individuals at risk even if the region as a whole has low future vulnerability to Lyme disease.

Giardiasis (caused by Giardia lamblia) and cryptosporidiosis (caused by Cryptosporidium parvum) are 2 important water-borne diseases in the M AR (Kocagil et al. 1999). Because of the difficulty in detecting and removing $C$. parvum from water supplies and the potential deadliness of cryptosporidiosis, this disease is of particular concern. This case illustrates, however, the difficulty and complexity associated with assessing indirect effects of climate change.

Cryptosporidiosis is caused by the protozoan Cryptosporidium parvum. Healthy individuals infected by $C$. parvum may experience watery diarrhea, headaches, abdominal cramps, nausea, vomiting, and low-grade fever. The disease can be fatal for people with compromised immune systems because there is no medical cure (J uranek 1995). The value to society of preventing contamination of drinking water with $\mathrm{C}$. parvum has been estimated to be a minimum of $\$ 211$ per statistical person (Kocagil et al. 1998). C. parvum enters the environment when shed in the feces of infected people, livestock or wildlife. Although there are many possible sources of C. parvum, an important one is cattle. Dairy and other livestock enterprises are important land uses in many M AR watersheds.

There are many factors involved that influence the potential impact of climate change on cryptosporidiosis risk, including characteristics of watersheds and water supply systems, how they will change in the future, how climate effects the disease organism, Cryptosporidium parvum, and its transport into waters used for drinking water or recreational uses. We have made considerable effort attempting to assess the impact of climate change on cryptosporidiosis risk. But the lack of data and lack of knowledge about the linkages between climate and $\mathrm{C}$. parvum viability, transport and infectivity make it a difficult relationship to quantify.

When Cryptosporidium parvum is present in a watershed, increased precipitation can cause greater surface water run-off and increase the transport of $C$. parvum into water supplies. Increased concentrations of $C$. parvum have been associated with rainfall in the Delaware River Basin (Atherholt et al. 1998). In addition, disease outbreaks have been observed during periods of heavy precipitation (Atherholt et al. 1998, Smith \& Rose 1998). Thus a wetter climate in the MAR could lead to higher $C$. parvum loads in water. But this assumes that there is a pool of $C$. parvum in the area. A bler \& Shortle (2000) suggest management of agricultural wastes will improve in the future and perhaps reduce the risk of $C$. parvum run-off. It is also possible that the amount of livestock in the region may decrease over time and that watershed protection will prevent what C. parvum is present from entering water supplies. Unfortunately, we are unable to quantify whether risk will increase or decrease because of the uncertainty involved.

If there is an increased risk of cryptosporidiosis in the MAR with climate change, private (individual) and public responses can be taken to reduce vulnerability to the disease. Public measures to reduce the risk of Cryptosporidium parvum entering water supplies include use of ground water, source water protection, and drinking water treatment practices, such as ozonation and specific types of filtration (Guerrant 1997). Groundwater systems, on average, have a lower risk from C. parvum than surface-water systems (Craun et al. 1996). However, groundwater systems have a 3-fold greater risk of a cryptosporidiosis outbreak if contamination occurs (Altherholt et al. 1998). Current and proposed EPA regulations will require surface-water systems classified as large or very large (serving over 10000 people) to have operational filtration systems 
that effectively remove $C$. parvum from drinking water supplies (US EPA 1998a). However, the filtration systems must be properly installed, monitored, and maintained to effectively reduce vulnerability to cryptosporidiosis. In addition, costs associated with upgrading and operating these water systems may be high. Some insight about the vulnerability of the MAR population to cryptosporidiosis can be gained by examining public water systems. As part of the ongoing MAR assessment, we are studying public water systems in the region.

Households can reduce their risks of contracting cryptosporidiosis from contaminated water supplies by such measures as boiling water or the use of especially designed home water filters or bottled water (J uranek et al. 1995). Like public measures, these actions are costly (Kocagil et al. 1998).

\subsection{Air quality}

Air quality, air pollutants, and human respiratory ailments have gained the interest of climate change scientists. This is in part because of established linkages with temperature and air pollutants (Lee 1993, WHO 1996). Without reductions in polluting emissions, heavily populated urban areas could experience more severe air quality problems as a result of climate change effects on the composition, concentration, and duration of chemical pollutants in the atmosphere (Sanderson 1992, Slanina et al. 1999). A key issue for assessing air quality risks is future emissions. The US has made significant progress in reducing air pollution since the 1970s (US EPA 1998b). Future emissions of air pollutants that are harmful to human health will depend on a variety of factors (e.g. automobile use, technology, regulations) that are not easily forecasted (Davies \& M azurek 1998). Because of the complexity (and uncertainties) of the linkages between climate change, air quality and human respiratory ailments, additional research is needed before making quantitative statements about potential health impacts in the region from changes in air quality induced by climate change.

\section{CONCLUSIONS}

Understanding the impacts of climate change on human health is essential for assessing the human dimensions of climate and evaluating mitigation and adaptation policies. Like many climate impact issues, the topic is, however, exceptionally complex. Uncertainties about future climates are compounded by limited information about critical linkages between climate and health, the futures of other health drivers, and the highly time- and location-specific character of many weather-related health risks.

M ortality directly related to heat, cold, storms, flooding and lightning is likely to continue to be very small in the MAR. Climate change could aggravate or contribute to the region's leading causes of death (heart disease, cancer, strokes), but lifestyle choices (smoking, diet, fitness) and genetic endowment are likely to continue to dominate the health status of the region. Although more speculative, climate change could increase the region's risk from water-borne and vectorborne diseases.

The view emerging from our assessment is that the MAR's technological and medical infrastructure should be able to prevent significant regional health problems from climate change. Thus, while health risks could increase, adaptive measures can be taken to reduce the region's vulnerability. However, it is important to emphasize that in conducting this assessment, we have assumed that climate change will not cause major shifts in ecosystems and weather conditions. In addition, there are economic costs associated with measures to reduce vulnerability. Accordingly, while health status may be little affected, the costs of public health would increase. There also may be subgroups with less access to public health measures. In addition, some adaptation measures can have undesirable side effects (e.g. secondary impacts of pesticides used to control disease vectors).

Historically, the US population has been able to adapt and reduce vulnerability to health risks. The health systems of the United States and other developed nations have experienced an incredible evolution over the past $150 \mathrm{yr}$, greatly improving the health status of their citizens and the capacity to manage public health risks (M cKeown 1976). For example, the crude mortality rate in 1900 was 1720 deaths per 100000 people and the life expectancy was $47.3 \mathrm{yr}$. By 1990, the crude mortality rate had dropped to 860 and life expectancy had increased to $75.4 \mathrm{yr}$ (Banta \& J onas 1996). A century ago the predominant health problems were epidemics of acute infections. Today, the major health risks are chronic diseases such as heart disease and cancer, which are strongly related to lifestyle choices (CDC 1998). The shift in the sources of health risks explains the changing emphasis in US health policy to issues such as access to health care (organizing the health care system to reach vulnerable populations) and promoting healthy behaviors (US DHHS, Public Health Service 1991). With continued investment in public health measures and barring significant unforeseen developments, major health policy challenges in the US during coming decades will relate to cost, access, and disparity in care (Kajander 1996, Grayson 1998). 
It is evident that further research is needed, particularly to increase our understanding of the indirect effects of climate change on health. Integrated modeling efforts are needed to quantify the complex biophysical and behavioral linkages connecting climate to health. Of equal importance is research on the costs, effectiveness and acceptability of adaptation options. Additional major research gaps are how climate change affects air pollution and motor vehicle accidents. Currently, motor vehicle fatalities are an important cause of death in the MAR, and thus the health consequences of climate change from such fatalities may be larger than other weather-related causes of death. Finally, research on the variation of health risks within the region by location and population characteristics is needed to address the distribution of climate-induced health impacts, especially because different segments of the population (e.g. elderly, poor, less educated) currently tend to face greater health risks in general.

Acknowledgements. This work has been sponsored by the US Environmental Protection Agency, under Cooperative Agreement No. CR 826554, and the Pennsylvania State University. We appreciate helpful comments from Ann Fisher, J anet Gamble, and Stephen M atthews, and the research assistance of Lubing Wang.

\section{LITERATURE CITED}

Abler DG, Shortle J S (2000) Climate change and agriculture in the Mid-Atlantic Region. Clim Res 14:185-194

Abler DG, Shortle J S, Rose A, Oladosu G (2000) Characterizing regional economic impacts and responses to climate change. Global Planet Change, in press

Altherholt TB, LeChevallier MW, Norton WD, Rosen J (1998) Effect of rainfall on Giardia and Crypto. J Am Water Works Assoc 90(9):66-80

Banta H, J onas D, J onas S (1996) Health and health care. In: Kovner AR (ed) J onas's health care delivery in the United States, 5th edn. Springer, New York, p 11-33

CDC (Centers for Disease Control and Prevention) (1998) Chronic diseases and their risk factors: the nation's leading causes of death. CDC, Atlanta, GA

CDC (1999a) M ortality patterns-United States, 1997. M M WR (M orb M ortal Wkly Rep) 48(30):664-668

CDC (1999b) Recommendations for the use of Lyme disease vaccine. M M WR (M orb M ortal Wkly Rep) 48(RR-7):1-26

Chestnut LG, Breffle W, Smith J (1995) Estimates of willingness to pay for potential changes in risks of mortality due to climate change. Final Report funded under US EPA Cooperative Agreement No. CR-817693, February 24, 1995. US EPA, Washington, DC

Chestnut LG, Breffle WS, Smith JB, Kalkstein LS (1998) Analysis of differences in hot-weather-related mortality across 44 U.S. metropolitan areas. Environ Sci Policy 1: 59-70

Colwell R, Epstein P, Gubler D, Hall M, Reiter P, Shukla J , Sprigg W, Takafuji E, Trtanj J (1998) Global climate change and infectious diseases. Emerg Infect Dis 4(3): 451-452
Craun GF, Calderon RL, Frost FJ (1996) An introduction to epidemiology. J Am Water Works Assoc 88(9):54-55

Davies J D, Mazurek J (1998) Pollution control in the United States. Evaluating the system. Resources for the Future, Washington, DC

Fisher A, Barron E, Yarnal B, Shortle J (1999) Climate change impacts in the Mid-Atlantic - a workshop report. Report to the US Environmental Protection Agency Office of Research and Development, Global Climate Change Research Program (Coop Agreement No. CR 826554-01) and Office of Policy (Coop Agreement No. CR 824369-01). US EPA, Washington, DC

Gibson J , (1999) M odeling Chesapeake Bay salinity and phytoplankton dynamics in response to varying climate. Master's thesis, The Pennsylvania State University, University Park

Glass GE (1995) Environmental risk factors for Lyme disease identified with geographic information systems. Am J Public Health 85(7):944-948

Grayson M (1998) Report offers a glimpse into the future of health care. Spectrum: J State Gov 71(2):1-3

Guerrant RL (1997) Cryptosporidiosis: an emerging, highly infectious threat. Emerg Infect Dis 3(1):51-57

Haines A, M cM ichael AJ (1997) Climate change and health: implications for research, monitoring and policy. Br Med J 315(7112):870-874

Houghton J T, J enkins GJ , Ephraums J J (eds) (1990) Climate change. The IPCC scientific assessment. Cambridge University Press, Cambridge

J ones CG, Ostfeld RS, Richard MP, Schauber EM, Wolff J O (1998) Chain reactions linking acorns to gypsy moth outbreaks and Lyme disease risk. Science 279(5353): 1023-1026

J uranek DD (1995) Cryptosporidiosis: sources of infection and guidelines for prevention. Clin Infect Dis 21:S57-61

J uranek DD, Addiss DG, Bartlett ME, Arrowood MJ , Colley DG, Kaplan J E, Perciasepe R, Elder J R, Regli SE, Berger PS (1995) Cryptosporidiosis and public health: workshop report. J Am Water Works A ssoc 87(9):69-80

Kajander J (1996) Future trends in the health care economy. J Health Care Fin 23(1):17-22

Kalkstein LS, Greene JS (1997) An evaluation of climate/ mortality relationships in large U.S. cities and the possible impacts of climate change. Environ Health Perspect 105(1):84-93

Kalkstein LS, Swift JJ (1998) An evaluation of climate/mortality relationships in the $\mathrm{M}$ id-Atlantic Region and the possible impacts of climate change. A report prepared for the Mid-Atlantic Regional Asessment. University of Delaware, Newark, DE

Kalkstein LS, M aunder WJ , J endritzky G (1996) Climate and human health, 2nd edn. World M eteorological Organization, Geneva

Kendall HW, Pimental D (1994) Constraints on the expansion of the global food supply. Ambio 23(3):198-205

Kilbourne EM (1997) Chap 12, Heat waves and hot environments. In: Noji EK (ed) The public health consequences of disasters. Oxford University Press, New York, p 245-269

Kocagil P, Demarteau N, Fisher A, Shortle J S (1998) The value of preventing Cryptosporidium contamination. Risk: Health Safety Environ 9:175-196

Kocagil P, Benson K, Shortle J (1999) Impacts of climate change on human health in the Mid-Atlantic Region. In: Fisher A (ed) The M id-Atlantic Regional Asessment Foundations Report. The Pennsylvania State University, University Park

Larsen U (1990) The effects of monthly temperature fluctua- 
tions on mortality in the United States from 1921 to 1985. Inter J Biometeorol 34:136-145

Lee D (1993) Climate change and air quality in London. Geography 78(1):77-79

Loeb PD (1985) The efficacy and cost effectiveness of motor vehicle inspection using cross-sectional data. South Econ J 52(2):500-509

McKeown T (1976) The modern rise of population. Academic Press, New York

McMichael AJ (1997) Global climate change: the potential effects on health. Br M ed J 315(7111):805-809

M cM ichael AJ and 20 others (1996) Chap 18, Human population health. In: Watson RT, Zinyowera M C, M oss RH (eds) Climate change, 1995: impacts, adaptations and mitigation of climate change: scientific-technical analyses: contribution of Working Group II to the second assessment report of the Intergovernmental Panel on Climate Change. Cambridge University Press, New York, p 561-584

Meltzer MI, Dennis DT, Orloski KA (1999) The cost effectiveness of vaccinating against Lyme disease. Emerg Infect Dis 5(3):321-328

NPA Data Service, Inc (1999) Regional economic projections series. NPA Data Service, Inc, Washington, DC

Patz J A (1996) Health adaptations to climate change: need for farsighted integrated approaches. In: Smith J B et al. (eds) Adapting to climate change. Springer, New York, p 451-464

Patz J A, Yap WY (1998) Regional impact assessment: human health-Mid Atlantic. A report prepared for the MidAtlantic Regional Assessment. J ohn Hopkins University, Baltimore

Patz J A, Epstein PR, Burke TA, Balbus J M (1996) Global climate change and emerging infectious diseases. J Am M ed Assoc 275(3):217-223
Polsky C, Allard J , Crane R, Yarnal B (2000) The M id-A tlantic Region and its climate: past, present, and future. Clim Res 14:161-173

Sanderson GF (1992) Climate change: the threat to human health. Futurist 26(2):34-38

Slanina J , ten Brink HM , Khlystov A (1999) Fate of products of degradation processes: consequences for climatic change. Chemosphere 38(6):1429-1444

Smith HV, Rose J B (1998) Waterborne cryptosporidiosis: current status. Parasitology Today 14(1):14-22

US Census Bureau (1998) Statistical abstract of the United States: 1998. US Department of Commerce, Washington, DC

US DHHS, Public Health Service (1991) Healthy people 2000: national health promotion and disease prevention objectives. DHHS publication no. (PHS)91-50213, US DHHS, Public Health Service, Washington, DC

US EPA (1998a) National primary drinking water regulations: interim enhanced surface water treatment; final rule. Federal Register 63(241)

US EPA (1998b) National air quality and emissions trends report, 1997. EPA Document No. 454/R-98-016, US EPA, Washington, DC

WHO (1990) Potential health effects of climatic change. World Health Organization, Geneva

WHO (1996) Climate change and human health. McMichael AJ , Haines A, Slooff R, Kovats S (eds) World Health Organization, Geneva

WHO (1998) The world health report 1998-life in the 21st century: a vision for all. World Health Organization, Geneva

Zlatoper TJ (1987) Testing for functional form and autocorreIation in the analysis of motor vehicle deaths. Q Rev Econ Fin 27(4):6-17 